\title{
The Bundling Strategy: The One-Click Effect on Loss Aversion
}

\author{
Juan Luis Nicolau \\ Virginia Tech \\ Ricardo Sellers \\ University of Alicante
}

Please, cite as:

Nicolau, J.L. and Sellers-Rubio, R. (2020) "The bundling strategy: the one-click effect on loss aversion". Journal of Hospitality \& Tourism Research. Vol. 44, n 4, pp. 704712. DOI: $10.1177 / 1096348019876692$

\begin{abstract}
:
This research aims to determine different levels of loss aversion in the context of price responsiveness and service bundling. Considering that nonlinearities in price responses may exist in a bundling strategy, this research tests the existence of different degrees of loss aversion, depending on whether an individual books one service independently of another (e.g., an airline ticket independently of accommodation) or as part of a bundle (e.g., a package that includes an airline ticket plus accommodation). We estimate a random parameter logit model. Empirical application shows that people who book a flight independently of accommodation are more loss averse than those who book a package that includes flight and accommodation. To explain this result, we propose the one-click effect so that people who find a price higher than expected (loss aversion) are more willing to accept it if the product is included in a bundle.
\end{abstract}

Keywords: bundling; booking; loss aversion; airfares; low cost 
Prospect theory devised by Kahneman and Tversky (1979) has been used in tourism to understand tourists' reactions to certain levels of attributes (most notably prices) and changes in personal characteristics (e.g., income). Furthermore, such theory has been used to study the influence that these attributes and characteristics can have on people's spending patterns and on their tourism choices, such as destinations or hotel rooms (Choi, Joe, \& Mattila, 2018; Masiero, Pan, \& Heo, 2016; Masiero \& Qiu, 2018; Nicolau, 2008; Smeral, 2012; Xu, 2018). According to this theory, the property of loss aversion plays a prominent role in explaining consumer behavior. This property leads people to react more strongly to losses than to gains when compared with their reference points.

In colloquial terms, the anger that people feel when losing a $\$ 100$ bill is greater than the joy of finding a $\$ 100$ bill; although the amount is the same in both situations, the negative outcome (anger) is greater than the positive feeling (joy). In the context of pricing, loss aversion emerges when the real price of a product is higher than the reference price (e.g., the expected price). Analogous to the example, the decrease in demand derived from finding a higher price than expected is greater than the increase in demand resulting from finding a lower price than expected.

This phenomenon still requires investigation in the context of a service component included in a tourism bundle. Accordingly, to the best of the authors' knowledge, this research applies, for the first time, the concept of loss aversion to pricing in the context of bundled tourism products. The relevance of this analysis is based on three points. First, excessive price reductions in tourism products can widen the region of loss aversion, rendering the reset of prices to "normal" levels more complex (Kalyanaram \& Little, 1994). For example, reducing the price from $\$ 100$ to $\$ 70$ would cause the reset of prices back to $\$ 100$ harder than lowering the price to $\$ 85$. The loss aversion region of $\$ 30$ in the former is more complex to handle than the loss aversion region of $\$ 15$ in the latter. Second, people can now book several components of a bundle with only one click (Ferrer-Rosell, Coenders, \& Marine-Roig, 2017). Third, air transportation and accommodation are the two central components in bundled tourism products (Josiassen \& Assaf, 2013). Therefore, a critical question arises: Who is more sensitive to deviations from the expected price (i.e., who is more averse)? The individual who books a flight independently of accommodation or the one who reserves a flight and accommodation together? This case is even more relevant today, given that firms drastically reduced their prices during the recent economic recession, and customers became accustomed to those lower prices.

However, firms are currently attempting to increase prices back to the precrisis levels. However, consumers may see this action as a huge increment in prices as they may have set those lower prices as their reference points.

The argument is that the price of a bundle might be processed differently compared with the prices of individual products. First, in the context of a bundled product, if the individual prices are not publicly shown, then, the actual price of each product is hidden. The latter will generate a lower risk of widening the region of loss aversion for that product. Second, if the individual prices are made publicly available, then, an extra processing mechanism involved emerges, as consumers must aggregate all prices. Thus, the reference price will be the total amount paid for the bundle in this one transaction. Consequently, this global reference price will be the reference point that consumers use 
in the next transaction; if the next transaction involves another bundled product, then, variations in individual prices have additional allowance to be volatile as long as the global price does not change substantially from the previous purchase. In this respect, variations in individual prices would have less effect on consumers' decision.

Service bundling has been a prevalent strategy in the tourism industry (Tanford, Erdem, \& Baloglu, 2011), encompassing a broad spectrum of applications, such as hotels (Maier \& Intrevado, 2018), IT-based platforms (Neidhardt \& Werthner, 2018), or tourism recommender systems (Sertkan, Neidhardt, \& Werthner, 2018). This preponderance is even more relevant these days, as people can design their desired combination of travel products by themselves.

Moreover, not only can they create their own set of products through online intermediaries they can also do so through providers: An especially salient example appears when people visit an airline's website to design a vacation package at a single price.

According to Abe (1998), pricing products included in a bundle can create intricate relationships and nonlinearities in consumer responses. This product bundling has relevant managerial implications, especially when using the mixed bundling strategy (rather than the pure bundling strategy). In this approach, the bundle is not only offered at one price but the bundled items can also be sold separately (and individual prices are visible). The enticement of the bundling strategy derives from the fact that the aggregated price for the bundle is lower than the addition of the individual prices. As people expect a bundle to offer a better value than independently purchased products (Heeler, Nguyen \& Buff, 2007), a "cushion" may exist for bundles in such a way that, when finding a price that is a little higher than expected, the reaction is less negative. Hence, they will be more prepared to "welcome" a rate that is higher than expected, so that the negative impact of finding a price higher than the consumer's reference price is smaller when booking a flight and accommodation together. While willingness to pay measures how much a person is predisposed to pay, loss aversion "captures" that predisposition by using a reference price (or an expected price); accordingly, deviations from an expected price could affect an individual's willingness to pay. Considering that air and accommodation services can be sold alone or together, the loss aversion phenomenon may have different effects depending on each context. Booking more than one service with "one click" is time efficient. Hence, individuals might be more predisposed (or realistically, less reluctant) to accept a higher-than-expected price. When booking through the airline's platform without even changing the webpage, they are obtaining all the services they are looking for in only one sitting, thereby saving time and reducing the effort in their information search. Considering this time efficiency and the perception that a bundle product is a better deal, consumers may be prepared to accept a higher price. Consequently, following these arguments about the inherent better deals and the higher time efficiency of bundled products, we hypothesize that the loss aversion of individuals who book airline tickets is lower when they book accommodation at the same time. Therefore, we propose the following hypotheses:

Hypothesis: The level of loss aversion of individuals that book flight only is not different from the level of loss aversion of those that book a bundle of flight and accommodations. 
To investigate the loss aversion property in a service bundling context - flight booked independently versus flight plus accommodation-prospect theory (Kahneman \& Tversky, 1979) is considered; therefore, gains and losses are introduced in the utility function (Klapper, Ebling, \& Temme, 2005). In the context of pricing, the central element is the price of the product, which will determine the existence of loss aversion. Accordingly, the utility function Uint for alternative $i$ and individual $n$ on occasion $t$ is expressed as

$$
\begin{aligned}
U_{\mathrm{int}}= & \alpha_{i}+\beta_{n} \text { GAIN }_{\mathrm{int}}+\zeta_{n} \operatorname{GAIN}_{\mathrm{int}}^{2}+\gamma_{n} \operatorname{LOSS}_{\mathrm{int}}+\eta_{n} \operatorname{LOSS}_{\mathrm{int}}^{2}+ \\
& \xi_{n} I S_{n} L O S S_{\mathrm{int}}+\varepsilon_{\mathrm{int}}
\end{aligned}
$$

where GAINint shows the excess of the reference price over the actual price of alternative $i$ for individual $n$ on occasion $t$; LOSSint is the excess of the actual price over the reference price; $I S n$ is a dummy variable with value 1 if the individual independently and separately books each service; otherwise, 0 . The central parameter for the analysis is $\xi n$ that will identify distinct levels of loss aversion according to the type of reservation ("flight booked independently of accommodation" or "flight plus accommodation"); loss aversion will be found if $\gamma n / \beta n>1$ (i.e., the coefficient that captures the effect of losses is larger than the coefficient associated with gains). Moreover, the quadratic terms allow us to explore the existence of diminishing sensitivity, which will be found if significant coefficients are obtained for the squares of losses and gains (in particular, a negative parameter $\zeta n$ and a positive parameter $\eta n$ ). Finally, eint is a random term that is identical and independently extreme value distributed; thus, a random parameter logit model is used. Given an individual $n$ making a decision on occasion $t$, the probability of an alternative $i$ being selected is defined as:

$$
P_{n t}(i)=\int_{\theta} \frac{\exp \left\{U_{\mathrm{int}}\right\}}{\sum_{j=1}^{J} \exp \left\{U_{j n t}\right\}} \phi(\theta \mid b, W) d \theta,
$$

where $J$ is the set of choice alternatives, and $\theta$ are the coefficients which are assumed to follow a density function $\varphi$. The latter is a normal distribution with average $b$ and variance $W$.

The sample was obtained at the Airport of Alicante-Elche (El Altet), Spain. Through personal face-to-face interviews using a structured questionnaire, the focus was on the Alicante-Gatwick route.

The dependent variable is a categorical variable that represents the set of alternatives (carrier types): low-cost, regular, and charter. The inclusion and distinction of these types of carriers as alternatives are important because of the effect of low-cost airlines on the number of passengers and on airfares (Khan, Kim, \& Kim, 2018; Vera Rebollo \& Ivars Baidal, 2009). With this information, the model estimates the parameters by looking at the probability of an individual rank ordering a set of alternatives in a specific way.

The independent variables are prices and reference prices, which are obtained, in line with Moon, Russell, and Duvvuri (2006), by looking at the distribution of prices found in the "shopping environment" on the shopping day. Accordingly, these prices are an 
external reference price and can be calculated by the mean of the actual prices of the alternatives available to each individual (the global mean value is $€ 351.8$ ). We use a stimulus-based reference price rather than an internal memory-based price standard because recent empirical results support the use of the former. In particular, Choi and Mattila (2018) found that people make their lodging decisions by relying more on external than on internal reference prices.

These authors argued that the "high accessibility" that external reference prices provide generates high levels of "perceived diagnosticity," which facilitates people's price evaluations. In other words, external reference prices allow people to observe easily and tangibly, the extent to which a price stands out in comparison with other product prices. Finally, individuals were asked whether they booked accommodation independently or in a bundle (56.1\% opted for booking independently).

Depending on whether individuals are booking items independently or in a bundle, different degrees of loss aversion can be observed through the random parameter logit model. Table 1 shows the parameter estimates. Before focusing on the parameter of interest $(\xi n)$ and seeing whether distinct degrees of loss aversion exist, the first question is as follows: Are people loss averse? The coefficient of gains is statistically insignificant, and the one associated with losses is positive and significant; thus, loss aversion seems to be supported. Concerning the square variables, the coefficient of gain2 is statistically insignificant, and the coefficient of loss 2 is positive and significant, which implies a presence of diminishing sensitivity only for losses.

As for the booking variable (ISn $\times$ LOSSint), we find a positive and significant parameter, $\xi n$. This result means that people who book a flight independently of accommodation are more loss averse than those who book the package "flight plus accommodation." Thus, the Alternative Hypothesis is supported, and the Null Hypothesis $(p<.01)$ that both groups show similar degrees of loss aversion is rejected.

The impact of a price which is higher than expected is negative in either case but is "less negative" when booking the package. This case is in line with the better deal and time efficiency that derive from the one-click effect proposed earlier, through which individuals could be more willing to accept a price which is higher than their expectations. Figure 1 depicts both effects and shows that the difference between the loss aversion existing in both types of reservations increases as the actual price moves further away from the reference point. 
Table 1

Different Degrees of Loss Aversion

\begin{tabular}{|c|c|c|}
\hline Independent Variables & $b$ & $S D$ of $\beta$ \\
\hline Gain & $-0.036(0.028)$ & \\
\hline Gain $^{2}$ & $0.0002(0.00017)$ & \\
\hline Loss & $0.099 \mathrm{~b}(0.044)$ & $0.010(0.007)$ \\
\hline Loss $^{2}$ & $0.0005^{\mathrm{b}}(0.0002)$ & $0.0001^{\mathrm{b}}(0.00006)$ \\
\hline Independently booking $\times$ Loss & $0.058^{a}(0.027)$ & $0.006(0.007)$ \\
\hline Constant LCC (low-cost carrier) & $-3.384^{\mathrm{b}}(1.371)$ & \\
\hline Constant RC (regular carrier) & $-4.526^{a}(1.506)$ & \\
\hline Maximum likelihood & \multicolumn{2}{|c|}{-54.55} \\
\hline Schwarz information criterion & \multicolumn{2}{|c|}{-65.27} \\
\hline Akaike information criterion & \multicolumn{2}{|c|}{-64.55} \\
\hline
\end{tabular}

aProbability $<1 \%$. bProbability $<5 \%$.

The distinct impacts of loss aversion, depending on whether people book a flight independently of accommodation or as part of a "flight plus accommodation" bundle, found in this study has important implications for future research. Specifically, as the bundling strategy is extensively employed in tourism, the detection of nonlinearities in price responses is a critical issue, as we find that specific mechanisms that lead some people to opt for a single alternative may exist and others to choose a bundled one. Further research should explore these mechanisms and the causes of the different outcomes. In this research, the relevant finding is that the one-click effect seems to have an effect on loss aversion.

Nonetheless, the reasons for this outcome are still to be uncovered. Regarding managerial implications, the different loss aversion sensitivities found for bundled and unbundled services should be considered by decision makers when they choose to vary prices. From an operational viewpoint, if people who buy a bundled product form their reference price from the global price paid for that bundle, then, variations in individual prices in future purchases might be imperceptible to these people. Accordingly, lowering prices and then returning them to normal might create different negative demand reactions, depending on whether the service is included in a bundle. More specifically, lowering prices excessively might reduce reference prices. The consequences of this situation are less dramatic in the context of bundled products, as the impact of loss aversion is lower for individuals booking bundled products. Price increases can generate drastic reactions in demand, especially in an environment where loss aversion has been proven to have an influence on consumer behavior. Accordingly, Kalyanaram and Winer (1995) recommended implementing small increments in prices to render them nearly imperceptible to consumers. However, determining the magnitude of these increments is a challenge, as they should be sufficiently small to not be fully noticed by the consumers but sufficiently large that the firm does not take forever to reach the intended price. Nevertheless, the use of bundled products might facilitate this goal. On the one hand, the pricing strategy becomes easily unnoticed by the consumers; on the other hand, if the product is included in a package, these increments do not have such a large impact on demand (compared with single products). According to the results obtained by this research, the loss aversion of people who book a bundled 
product is lower. As found by Dolasinski, Roberts, and Zheng (2019), today's business is not only about price because timing and channel make a difference as well; specifically, finding the right timing for a sequentially designed pricing strategy (e.g., small variations in price) and the right choice of distribution channel (e.g., online travel agency, airline's website, opaque channel) to implement that strategy is key to its success.

\section{References}

Abe, M. (1998). Measuring consumer, nonlinear brand choice response to price. Journal of Retailing, 74, 541-568.

Choi, C., Joe, S. J., \& Mattila, A. S. (2018). Reference price and its asymmetric effects on price evaluations: The moderating role of gender. Cornell Hospitality Quarterly, 59, 189-194.

Choi, C., \& Mattila, A. S. (2018). The effects of internal and external reference prices on travelers' price evaluations. Journal of Travel Research, 57, 1068-1077.

Dolasinski, M. J., Roberts, C., \& Zheng, T. (2019). Measuring hotel channel mix: A DEA-BSC model. Journal of Hospitality \& Tourism Research, 43, 188-209.

Ferrer-Rosell, B., Coenders, G., \& Marine-Roig, E. (2017). Is planning through the Internet (un)related to trip satisfaction? Information Technology \& Tourism, 17, 229-244.

Heeler, R. M., Nguyen, A., \& Buff, C. (2007). Bundles = discount? Revisiting complex theories of bundle effects. Journal of Product \& Brand Management, 16, 492-500.

Josiassen, A., \& Assaf, G. (2013). Look at me-I am flying: The influence of social visibility of consumption on tourism demand. Annals of Tourism Research, 40, 155175.

Kahneman, D., \& Tversky, A. (1979). Prospect theory: An analysis of decision under risk. Econometrica, 47, 263-291.

Kalyanaram, G., \& Little, J. D. C. (1994). An empirical analysis of latitude of price acceptance in consumer package goods. Journal of Consumer Research, 21, 408-418. Kalyanaram, G., \& Winer, R. (1995). Empirical generalizations from reference price research. Marketing Science, 14, 161-169.

Khan, N. T., Kim, Y. H., \& Kim, Y. B. (2018). The dynamic impact of low-cost carriers on full-service carriers and the tourism industry of South Korea: A competitive analysis using the Lotka-Volterra model. Asia Pacific Journal of Tourism Research, 23, 656-666.

Klapper, D., Ebling, C., \& Temme, J. (2005). Another look at loss aversion in brand choice data: Can we characterize the loss averse consumer? International Journal of Research in Marketing, 22, 239-254.

Maier, T., \& Intrevado, P. (2018). Function space revenue management: A product bundling approach to hotel function space utilization. Journal of Convention \& Event Tourism, 19, 188-203.

Masiero, L., Pan, B., \& Heo, C. (2016). Asymmetric preference in hotel room choice and implications on revenue management. International Journal of Hospitality Management, 56, 18-27.

Masiero, L., \& Qiu, R. T. R. (2018). Modeling reference experience in destination choice. Annals of Tourism Research, 72, 58-74.

Moon, S., Russell, G. J., \& Duvvuri, S. D. (2006). Profiling the reference price consumer. Journal of Retailing, 82, 1-11. 
Neidhardt, J., \& Werthner, H. (2018). IT and tourism: Still a hot topic, but do not forget IT. Information Technology \& Tourism, 20, 1-7.

Nicolau, J. L. (2008). Testing reference dependence, loss aversion and diminishing sensitivity in Spanish tourism. Investigaciones Económicas, 32, 231-255.

Sertkan, M., Neidhardt, J., \& Werthner, H. (2018). What is the "personality" of a tourism destination? Information Technology \& Tourism, 21, 105-133.

Smeral, E. (2012). International tourism demand and the business cycle. Annals of Tourism Research, 39, 379-400.

Tanford, S., Erdem, M., \& Baloglu, S. (2011). Price transparency of bundled vacation packages. Journal of Hospitality \& Tourism Research, 35, 213-234.

Vera Rebollo, J. F., \& Ivars Baidal, J. A. (2009). Spread of low-cost carriers: Tourism and regional policy effects in Spain. Regional Studies, 43, 559-570.

$\mathrm{Xu}, \mathrm{X}$. (2018). Examining the relevance of online customer textual reviews on hotels' product and service attributes. Journal of Hospitality \& Tourism Research, 43, 141-163. 